\title{
Triskelion Structured Colloidal Quantum Dots Supporting Information
}

\author{
Richard D. Edwards, Harold P. Hodgins, Ian P. Hamilton
}

Department of Chemistry and Biochemistry, Wilfrid Laurier University, Waterloo, $\mathrm{N}_{2} \mathrm{~L}_{3} \mathrm{C}_{5}$, Ontario, Canada

Equation for calculating the smoothed CD spectra:

$$
\sum_{i=1}^{i=n} 0.02456756 \frac{v_{i} E_{i}}{\delta e} \times e^{-\left(\frac{v-v_{i}}{\delta e}\right)}
$$

Here $\delta \mathrm{e}=\mathrm{o} .8$ and, for line $i, \mathrm{v}_{i}=\mathrm{R}$ (velocity) and $E_{i}=$ energy in $\mathrm{eV}$.

Stephens, P. J.; Harada, N. "ECD Cotton Effect Approximated by the Gaussian Curve and Other Methods." Chirality 2010, 22, 229233.

Details of AIMD calculations: To control the temperature we used the Nosé-Hoover approach as implemented in the $\mathrm{CP}_{2} \mathrm{~K}$ software package. ${ }^{33}$ The time step was 2 fs for calculations without $\mathrm{H}$ atoms and $0.5 \mathrm{fs}$ for calculations with $\mathrm{H}$ atoms. All calculations went from $77 \mathrm{~K}$ to $188 \mathrm{~K}$ to $298 \mathrm{~K}$. The temperature tolerance was $20^{\circ}$ at $77 \mathrm{~K}, 35^{\circ}$ at $188 \mathrm{~K}$, and $50^{\circ}$ at $298 \mathrm{~K}$.
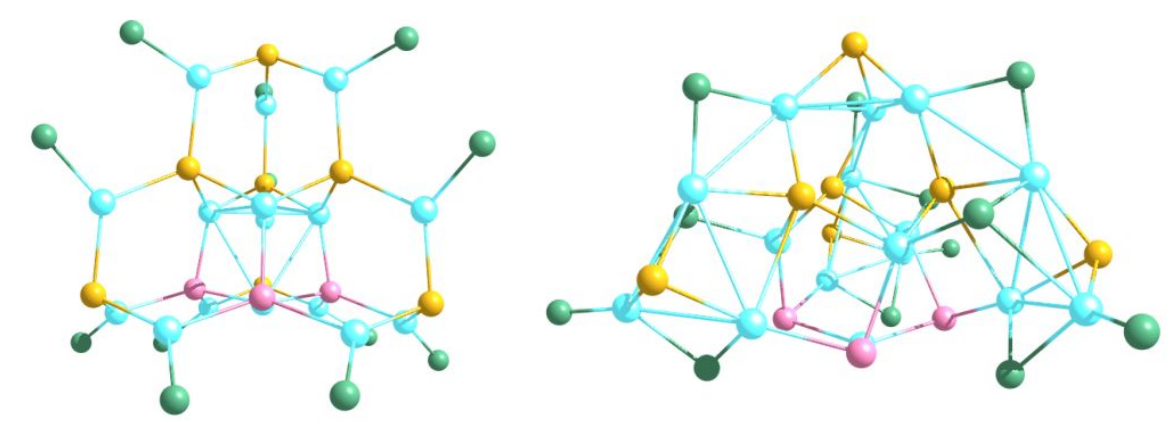

Figure S1. Top view of initial (left) and optimized (right) $\mathrm{Cd}_{16} \mathrm{Se}_{7} \mathrm{Te}_{3} \mathrm{Cl}_{12}$ structure. 

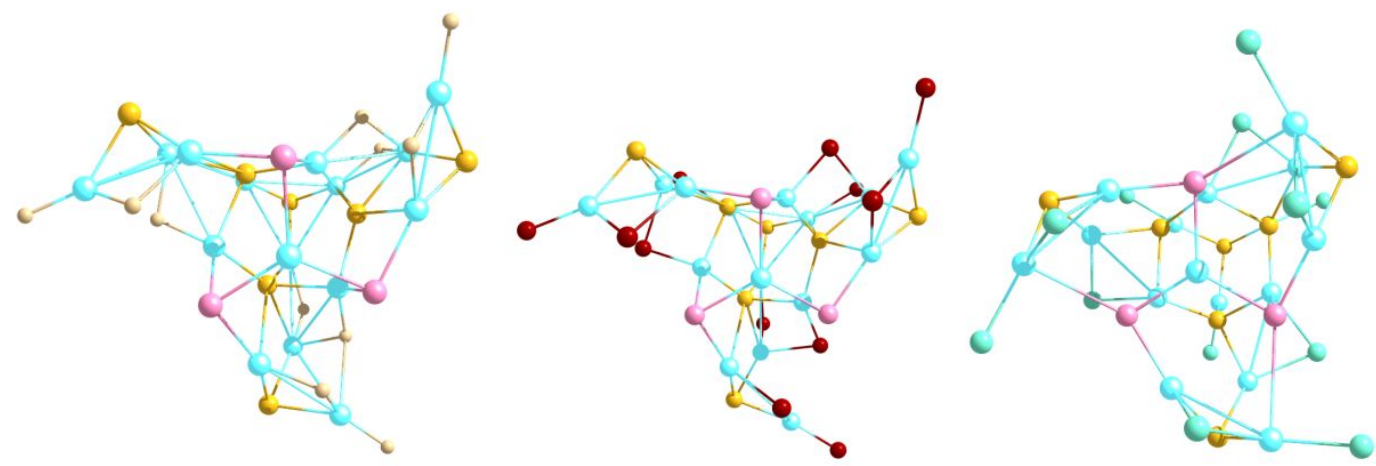

Figure S2. Side views of optimized $\mathrm{Cd}_{16} \mathrm{Se}_{7} \mathrm{Te}_{3} \mathrm{X}_{12}$ structures, $\mathrm{X}=\mathrm{F}$ (left), $\mathrm{Br}$ (middle), and I (right). The $\mathrm{Cd}_{16} \mathrm{Se}_{7} \mathrm{Te}_{3} \mathrm{~F}_{12}$ triskelion structure was not formed upon optimization of the initial structure but was formed upon undergoing AIMD at 77 K.

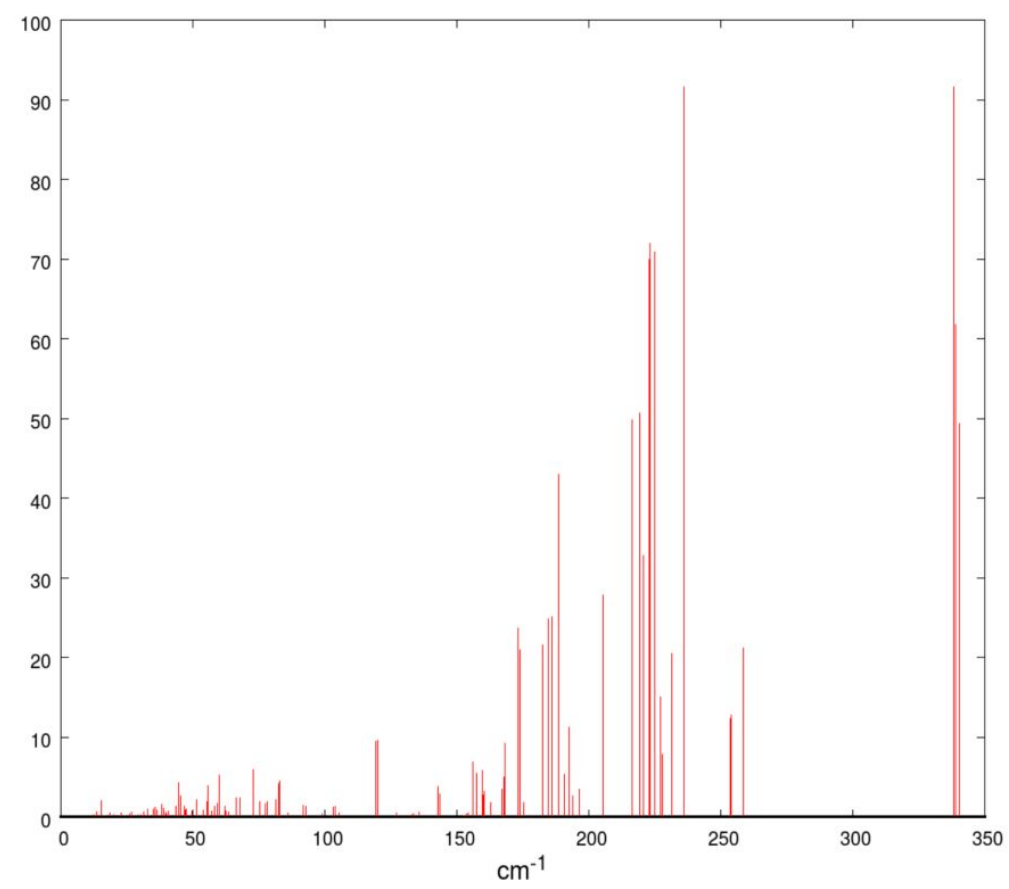

Figure $\mathrm{S}_{3}$. The IR line spectrum for $\mathrm{Cd}_{16} \mathrm{Se}_{7} \mathrm{Te}_{3} \mathrm{Cl}_{12}$

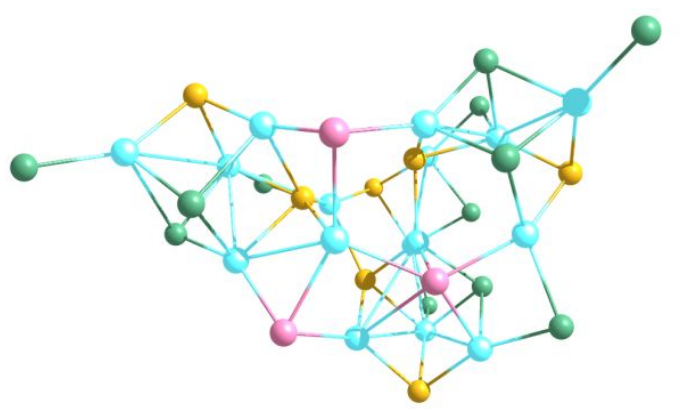

Figure $\mathrm{S}_{4}$. Side view of the collapsed $\mathrm{Cd}_{16} \mathrm{Se}_{7} \mathrm{Te}_{3} \mathrm{Cl}_{12}$ structure. The $\mathrm{Cl}$ atom at the tip of one of the legs is still bonded to the same $\mathrm{Cd}$ atom but it is now also bonded to another $\mathrm{Cd}$ atom. 

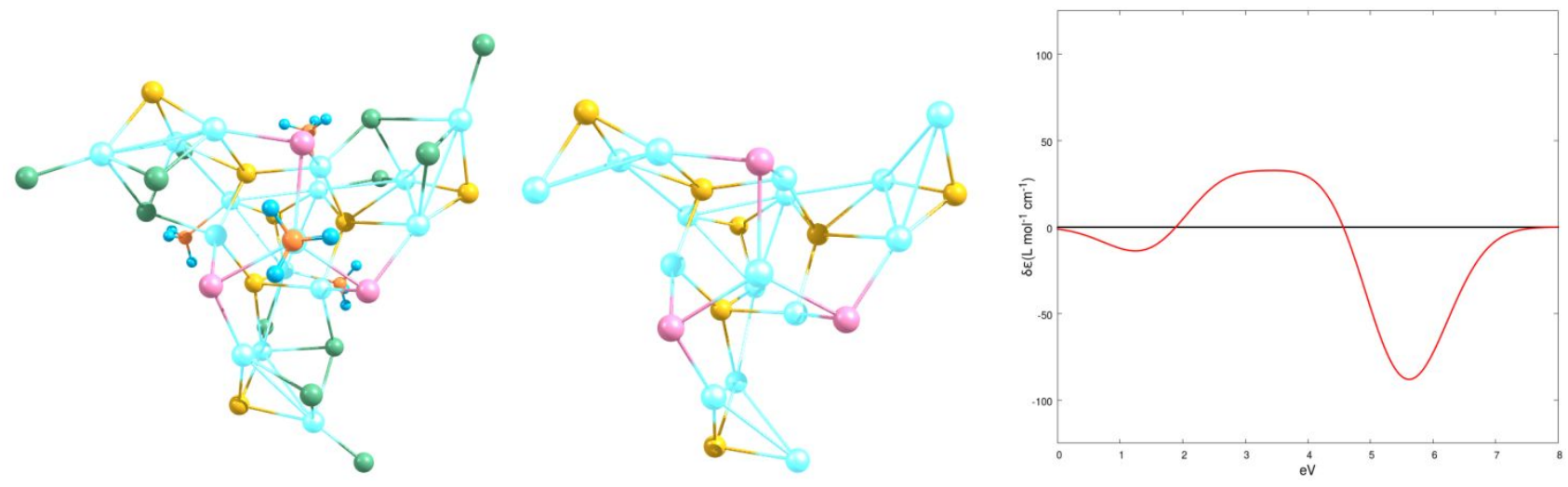

Figure $\mathrm{S}_{5}$. Side view of $\mathrm{Cd}_{16} \mathrm{Se}_{7} \mathrm{Te}_{3} \mathrm{Cl}_{12}\left(\mathrm{NH}_{3}\right)_{4}$ optimized structure (left panel); $\mathrm{Cd}_{16} \mathrm{Se}_{7} \mathrm{Te}_{3}$ core (middle panel); $\mathrm{CD}$ spectrum of core (right panel).

Acknowledgements I.P.H. acknowledges financial support from NSERC, SOSCIP, Compute Canada, and Wilfrid Laurier University.

Author Contributions R.D.E., H.P.H., and I.P.H. collaborated on all aspects of this work.

Author Information The authors declare no competing financial interest. Correspondence should be addressed to (ihamilton@wlu). 